\title{
DEVELOPMENT OF MEDICAL CULTURE IN THE EAST-EUROPEAN PART OF RUSSIA (THE PECHORA BASIN)
}

\author{
${ }^{1}$ Nuzhny V.P., ${ }^{2}$ Ilyina I.V., ${ }^{3}$ Nuzhnaya T.G., ${ }^{1}$ Kibler N.A., ${ }^{1}$ Shmakov D.N. \\ ${ }^{1}$ Institute of Physiology, Komi Science Centre, Ural Branch, Russian Academy of Sciences, \\ Syktyvkar,e-mail:shmakov@physiol.komisc.ru; \\ ${ }^{2}$ Institute of Language, Literature and History; Komi Science Centre, Ural Branch, \\ Russian Academy of Sciences, Syktyvkar; \\ ${ }^{3}$ Syktyvkar State University named after Pitirim Sorokin, Syktyvkar
}

\begin{abstract}
Various systems of medical care that existed in the Pechora basin, developed in connection with the geographical and economic situation of the region, and their impact on the medical culture of the population are considered. For centuries, the medical culture of the population of the Pechora basin was determined by knowledge, based on oral tradition and ascending to the folk experience. Zemstvo medicine has created new organizational forms of medical care for the population. However, the effectiveness of the official medicine was extremely low. During the first quarter of the XX century there were no significant changes in the field of health care. For the development of industrial reserves of the Komi, the era of the Gulag began. Despite the declared measures to preserve the labor force, prisoners did not receive adequate medical care. The post-gulag soviet medicine has created one of the most perfect paternalistic models of cost-effective health care system. The "historical dead-ends" of medical care development, influencing the formation of medical culture in modern society are shown. The role of the historically developed paternalistic approach in providing medical care is estimated. The reasons hindering the development of medical consumption culture are determined.
\end{abstract}

Keywords: medical anthropology, the system of medical care, ethnic group

Considering the problems of medical anthropology of the Pechora basin, one should take into account the ethno-cultural originality of this region [7, p. 171-172]. First of all, this is the territory of contacts of three ethnic groups - the Komi, the northern Russians and the Nenets, belonging to different economic and cultural types and ideological systems, which initially affected both the peculiarities of the folk-medical practices and the attitude to official medicine. In the historical context, there is also a unique situation when the indigenous and old-resident population is the bearer of the traditions of several forms of health care systems: traditional folk medicine, health care of the early Soviet period, the medical system of the Gulag, the late Soviet health care.

\section{The traditional folk medicine}

For centuries, the medical culture of the population of the Pechora basin was determined by knowledge, based on oral tradition and ascending to the folk experience. Assessing the level of development of folk healing in the second half of the XIX century, Dr A. Drzevetsky wrote that folk medicine of the Komi "is rich both in its means and its leaders, which it is not easy to compete with" $[1$, p. 45].

The transfer and preservation of special knowledge was provided by cultural mechanisms that acted in the form of family and social traditions, as well as sufficiently stable ideas and rituals. Training the healing occurred during the process of daily medical, religious and religious magical practice, that provided the transfer of important and valuable for the ethnos information to the next generation and imposed certain ethical obligations on the recipient of specific information and skills. With all the variety of techniques and methods of treatment depending on the disease, the individual skills of the doctor, his behavior during the delivery of medical care has an important common feature: the constant connection between the doctor and the patient in the process of treatment, which has been one of the important reasons for the effectiveness of traditional medicine. The doctors knew the limits of their capabilities, did not undertake the treatment of diseases beyond their control: "... they still remained alive, I got them back on their feet. Only one died. She got hurt at the logging site. They have brought: can you, say help? I touched, and right under my fingers I felt the blood spurting from the ragged veins. Her, I say, take her somewhere quicker to the hospital. There is nothing I can do for her" [3, p. 18]. "I can heal a man, and cattle, and a cat, even a dog. Only I can not cure appendicitis and cancer" [3, p. 18].

The activities of folk healers were under strict censorship of the collective, the emergence of all sorts of charlatans in the traditional village community was excluded. In traditional culture, the introduction of sacral knowledge and the acquisition of power imposed on the 
individual special ethical obligations, the most important being the prohibition of commercialization of medical activities, which was manifested in the refusal of the healers not only from the monetary remuneration, but also from direct cooperation within any institution for a fee: "You yourself somehow heal, since you have such a job, but I can not afford it for money" [3, p. 37].

Given that the Pechora basin area is the territory of contacts of three ethnic groups, the question of mutual attitude of the Komi, Russians and Nenets to the healers of the neighbors is of interest. The researchers noted the facts of a special respectful attitude of peoples to the sacred persons of another ethnic group, "the Russians and Komi listened to the prophecies of the Nenets shamans", and "the Nenets turned to the Khanty shamans, considering them stronger" [4, p. 282]. Zyryan region was famous among the Russians as the land of sorcerers "known for their art to unleash the disease and to cure them" $[8$, p. 18;9, p. 69], while surrounding people were afraid of the inhabitants of Ust-Tsilma and Pinega calling them sorcerers, drug-whisperers were in great respect. Assessing the activity of folk healers, it is necessary to note the factors that contributed to the preservation to our days of the institution of quackery. In the process of treatment, along with therapeutic and magical rituals there were included the means, the healing properties of which were revealed in the course of centuries of observations of nature and everyday practical activities for its development. In addition, with the undivided belief of the patient and those around him in the efficacy of the traditional treatment and the power of the healer, magical rites caused considerable psychotherapeutic effect, which itself could have a positive therapeutic effect. There is no doubt, that the majority of folk healers are exceptionally bright personalities with special, often extraordinary abilities. To date, they are the main carriers of the historical memory of traditional medical culture and keepers of institutional knowledge about folk remedies and methods of treatment.

\section{The development of the public health system is connected with the activity of the Zemstvo}

Prior to its formation in 1869 , there were no stationary medical facilities in the Pechora district, "the doctor, having found himself in front of 70,000 of his patients, scattered on 137,196 square miles, should only hopelessly spread his hands: "Well, brothers! Do it as you know. If you want to live - live, if you want to die - die!" [9, p.18]. Zemstvo medicine has created new organizational forms of medical care for the popu- lation. Zemstvo doctors of the Pechora district D.A. Arkhangelsky, E.A. Panov, A.O. Shidlovsky, A.I. Markova and others, who worked at different times from 1870 to 1914 , did much to improve health care for the inhabitants of the region. The traveling system was replaced by a mixed one, and then by a stationary one. Two medical stations with centers in the village of Ust-Tsilma and Mokhcha were formed. Medical personnel was increased and the posts of district doctors were introduced. The duties of the district doctor included the organization of medical care in the hospital and the management of the pharmacy, control of paramedics, midwives, smallpox-vaccinators, personal participation in the treatment at home of the seriously ill and help in difficult childbirths, taking measures for the prevention of epidemics, maintaining medical statistics and reporting to the Zemstvo board. However, "rarely where the medical helplessness of the population is felt so much as in the Pechora region. In the District with the population of 37,253 people living in villages located at great distances, with archaic ways of communication, there are only two district doctors, 6 paramedics, 4 midwives and 9 volost smallpox-vaccinators from peasants or retired soldiers. In the summer of 1903, to the question of who is treating you in case of illness, in most of the villages the answer was: "the doctor comes 1-2 times a year," "neither the doctor nor the paramedic have ever been here," "the paramedic comes once a year to impart smallpox to children" [6, p. 230]. Most of the time hospitals and medical points were left without specialists, since "doctors, like other employees, look at their life in Pechora as a temporary residence, always living with a constant thought and hope for a new place with greater comfort of life" [ 6 , p. 245]. The main burden fell on the paramedics, who had to travel to large distances, reproducing the ineffective travelling system of medical care which the Zemstvo medicine tried to avoid. All above had led to the fact that not only the effectiveness, but also the authority of the official medicine was extremely low. In the Pechora region in 1903, out of 1,043 interrogated patients 19 people were treated by veterinarian, 177 by midwives and healers, 262 - "by their own means," 41 - "at disease they turned to God", 394 - not treated at all and only 150 people went to a doctor or a paramedic [6, p. 210]. It is very indicative that, despite a significant change in the medical culture of the indigenous population over the past century, the Pechora villages remain quite critical to the public health system. Ethnographic research at the turn of the XX-XXI centuries recorded the existence in many settlements of the Pechora area of practicing folk 
healers: herbalists, bonesetters, bloodletters, up to healers of narrow specialization among the Nenets and Komi reindeer herders of Izhma, which is a typical example of the effect of economic activities of the people on the structure of medical knowledge [2, p.178-179; 3, p. 34].

\section{The health of the early Soviet period}

The level of health care services significantly decreased due to the 1-st World War of 1914, and during the first quarter of the century there were no significant changes in the field of health care. The revolutionary events in the early 1919 in the Pechora District were accompanied by a severe public health crisis caused by the lack of medicines and medical equipment, as well as medical workers under repression. Realizing the serious social threat of the collapse of the health care system and the Russian economy as a whole, the Russian Communist Party (Bolsheviks) in March 1919 at its VIII Congress defined the tasks of public health: combating social diseases and epidemics, sanitation measures for the improvement of health of the populated areas, providing the population with free qualified medical and drug assistance [10, p. 163-171]. In August 1921, the Regional Committee of Health of the Komi Autonomous Region started creating the hospital and outpatient network, which was due to the adaptation of houses for them, from which families of the former merchants, kulaks and clergy were evicted. The state, like in the second half of the XIX century, practically refused to participate in the organization of public health care at the proper level.

\section{The medical system of the Gulag (General Directorate of Camps)}

Rapid industrial development had particular influence on the formation of the specifics of health care of the Komi region. By the decree of the Soviet of People's Commissars of the USSR of July 11, 1929 the Chief Political Administration was entrusted with the task of developing the economic life of the least accessible, the most difficult for development and at the same time possessing huge natural riches the country's outskirts through the use of labor of isolated socially dangerous elements by colonizing the sparsely populated places. In the Pechora region, comprehensive exploration and development of coal and oil fields, as well as accelerated road construction and laying of the railway, were to begin. The implementation of this program without extreme measures to attract labor force was impossible, and the Komi region in the 1930s-1940s became the place of exile, special settlements and camps for prison- ers. For the development of industrial reserves of the Komi, the "great migration of peoples", the era of the Gulag began, which absorbed the nascent Soviet health care and pushed back the development of medical care, especially in the remote places. In 1937 in the Pechora basin, for the exploration and development of natural resources of the Far North, the Pechorsky forced labour camp was organized - for barge-building, in Troitsk-Pechora and Kozhva logging enterprises - forced labour camp for logging, where to labor settlers from kulaks, residents of Western Ukraine and Belarus, Poland, Lithuania were sent. For the settlers to successfully "build socialism", it was necessary to provide them with acceptable housing, canteens, baths, medical posts, hospitals, social care institutions, clubs, etc. [5]. Considering that there were many children among the settlers, nurseries, kindergartens, schools were needed. It was necessary to provide these institutions with appropriate facilities, equipment, personnel, and find funds for their maintenance. In the Gulag contract of the People's Commissariat of Internal Affairs and the People's Commissariat for Forestry of the USSR it was determined that "medical services for special settlers and members of their families are carried out by medical and preventive institutions located on the territory of the enterprise of the People's Commissariat for Forestry of the USSR on a common basis with other workers. In case of absence of medical facilities on the territory of the enterprise, special settlers and members of their families are served by the general network of public health authorities on the same grounds as other workers of these enterprises". Logging enterprises could not cope with this task, so the solution of social issues was postponed "for later". It is here that you can find the reasons for the beginning contradictory attitude to the health care system, which exists in the mass consciousness of the population. On the one hand, it is the boundless trust in the treating doctor, on the other hand the boundless distrust to the health care system and officials. The established health service of the Gulag was guided by the principles inherent in the Soviet health care: planning, centralized management, comprehensive approach to treatment, free of charge, preventive orientation, repeated the main stages of its development as one of the departmental structures of the Soviet medicine. But much more it was connected with the history of the development of the Gulag itself. The tasks of the Gulag health service included: regulation of labor use of prisoners, being the main factor in preserving their physical condition, organization of measures to improve 
the health of prisoners, carrying out measures to reduce morbidity. By order of the Gulag, prisoners were divided into a balance contingent (full workforce) and an out-of-balance contingent (sick, disabled, etc.). All above, was in line with the basic strategy of the Soviet public health care: active participation in solving the problem of preservation of labor resources. Despite the declared measures to preserve the labor force, despite the most important principle of corrective labor policy being mandatory for camps "punishment should not pursue the purpose of causing physical suffering or humiliation of the human dignity of convicts", prisoners were subjected to both severe physical and moral humiliation, did not receive adequate medical care. Specific for the Gulag treatment-and-prophylactic institutions were the so-called health centers and health teams. It was recommended to widely use labor therapy, physiotherapy exercises, organization of rest of prisoners in the open air. Treatment of employees, civilians and members of their families was carried out under the same conditions, i.e. all were hostages of the same system.

\section{The late medical system of the Soviet period}

The post-Gulag soviet medicine has created one of the most perfect paternalistic models of cost-effective health care system, based on the declared accessibility, strong influence of inpatient care as the main pattern in the structure of health care. At the same time the remote places, "bear corners" were left to themselves. Formed over the decades of exploitation of the resources the focal and dispersed form of population settling in the Pechora basin came into conflict with the modern trends of industrial development of the Republic and the system of providing quality medical care. Together with the archaic market economy, the Pechora river went out of human control; the lack of river drainage, bottom dredging works, arrangement of the banks had led to a significant deterioration of water flow: floods became more destructive, number of backwaters increased, the channel became shallow. End-to-end navigation became very difficult. Such a situation had reduced the level and quality of life of the population of the Pechora basin. The fact is not even in an economic component, but in the socio-cultural aspect of life.

It is important that in the population the level of auto-identity of native places decreased. The self-identification of ethnic groups decreased, the tendencies of social autism intensified. The Pechora river from the system-forming is currently becoming a system of separation. In these circumstances it is difficult to speak about the medical culture, the culture of consumption of medical services, the role of health care reforms. The upper reaches of the Pechora river still represent a remote place where the dissatisfaction with the state of modern healthcare is clearly manifested, medical aid is not effective enough, all this being the reason for the dissociation of the effect of overestimated expectations from medical services and the real state of medicine. It is in these "bear corners" that the dissatisfaction of the population with medicine is clearly manifested. The culture of consumption of medical services remains at an unorganized level, which leads to the inversion of the declared medical care towards archaism. At present the attention is drawn to the constant increase in the number of the smallest settlements with the population of up to 50 people. Most of them (over $80 \%$ ) are villages with the predominance of the population of Komi nationality. More than half $(54 \%)$ of all rural settlements are villages with up to 200 inhabitants, in which only some institutions of the service sector are created selectively. Over $3 / 4$ of all settlements (557 settlements) do not have a demographic base for creating a full range of cultural and consumer services for the population. In the settlements with the predominance of the Komi nationality, the population is up to 200 people $-63 \%$, up to 500 people $84 \%$ of the settlements. With such a fractional network of settlements, it is difficult to solve the problems of the functioning of social service facilities, medical assistance, transport network development etc.

In many rural settlements with a total population of 38,484 people ( $4.3 \%$ of the total population of the Republic of Komi) medical services are not provided. Rural hospitals are often converted to outpatient clinics, pharmacies - to the category of drugstore points, pre-existing outpatient clinics are closed; there are corresponding changes in the number and structure of medical personnel, financing, supply of medical products. Despite the fact that Troitsk-Pechora, UstTsilma and Izhma regions are located in similar natural and climatic conditions, geographical remoteness and limited communication, territorial isolation contributed to the striking differences in the culture and way of life of the population living on these territories. In the Izhma region more than $85 \%$ of the population are the Izhma Komi; in Ust-Tsilma region over $85 \%$ are the Russians, old believers who moved to these territories as a result of forced migration, many generations ago; in Troitsk-Pechora region $63.9 \%$ are the Russians, $26.2 \%$ - the Komi. Given the specifics of the development of the Russian and Soviet society, where the paternalistic model 
has always been and remains the most psychologically acceptable, the question arises whether this model of the doctor-patient relationships is optimal for solving ethical and social problems that arise during treatment at the present stage of health care development? Of course, medical care, and the health care system are focused on restoring health as a physical component to perform professional physical labor. At the same time, the ongoing processes in health care do not contribute to the formation of medical culture in the population, but on the contrary, create a negative attitude to medicine. As a result, the population does not have a positive attitude to a healthy lifestyle and medical culture.

The social order in healthcare should not ignore the historical and ethnic peculiarities in the Komi Republic, since the object of medical care is a man who is more connected with ethnogenetic and historical and cultural factors that determine his attitude to health care and the health system as a whole. These factors determine the degree of his compliance in his interaction with the system, are decisive in the formation of the medical culture of the population. The social order should take into account the continuing trend of the contradictory attitude to the health care system that exists in the mass consciousness, on the one hand it is boundless trust to the attending physician, on the other hand - an equally boundless distrust to the healthcare system and medical officials. Paternalistic moods are now more common to patients, their behavior in relation to their health is formed on the basis of: a) low level of competence in medicine, b) large neuropsychic overloads and the desire to shift some of their concerns on the shoulders of a doctor, c) disorientation in new forms of medical services, prices and drugs. Medicine is perceived by society as a pattern, as part of a regulated plan, as a duty on the part of the state, and the list of medical services is considered as an official set which is correct and which does not accept alternative methods of treatment and diagnosis. Folk medicine in this context serves as part of the informal culture of indigenous peoples, as an underground of the official medical culture. This internal conflict of the official and folk medicine does not allow to integrate knowledge, creates discomfort in a part of the population. The ineffectiveness of the mobilization system of health care contributed to the fact that the ideas of diseases, the ideas about health in the population remained archaic in the religious and mythological aspect, while the population itself remained isolated or distrusted to the health care system, which does not try to change anything. The system of folk medicine in modern society, instead of coexisting and integrating into the health care system, remained isolated. At the same time, most of the state's expenditures on public health, the folk medicine could take on itself, especially in preventing diseases and maintaining a healthy lifestyle. Awareness of our society of its heterogeneity not only social but also cultural, will allow more rational use of health resources, integrally approach to the health of the nation, taking into account the socio-economic, ethno-cultural and medical heritage.

Thus, the various medical care systems that existed on the territory of the Pechora basin formed on the basis of the geographical and economic location of the region, are considered. The formed health care systems, including modern ones, are concentrated mainly on restoring physical health to perform a certain work activity, they lack the concept of health as a value category. If to consider health as a value category, determining the quality and life expectancy of an individual in the future, then the health and medical requirements should be different. Health care should move away from the model of service delivery to the model of improving the quality of life in which the health care for patients will be considered in terms of improving not only the quality of the service itself, but also its impact on the quality of life and its duration, while for the state the medical service will be part of the creation of an economic product. Folk medicine, which is based on institutional instincts of self-preservation, rather than medical technologies, should become part of the medical culture of modern society, as it is one of the forms of the auto-identity of the ethnic group.

\section{References}

1. Drzhevetsky A.I. Medical-topography of Ust-Sysolsky Uyezd. St. Petersburg, 1872. - 106 p.

2. Ilyina I.V. Komi folk medicine // Atlas of the Republic of Komi. - M.: Izd. "Design. Information. Cartography", 2001. P. 178-181.

3. Ilyina I.V. Traditional medical culture of the peoples of the European North-East. - Syktyvkar, 2008. - 326 p.

4. Khomich L.V. Shamans of the Nenets // Problems of the History of the Public Consciousness of the Aborigines of Siberia. - L.: Nauka, 1981. - 284 p.

5. Kokurin A.I., Petrov N.V. Russia 20th Century. Documentation. GULAG (General Directorate of Camps). 19171960. - M.: MFD, 888 p.

6. Martynov S.V. Pechora region. St. Petersburg, 1905. - 276 p.

7. Nuzhniy V.P., Ilyina I.V., Nuzhnaya T.G., Kibler N.A. Medical anthropology of the Pechora river basin // Izvestiya Komi Branch of the Russian Geographical Society. Materials of the Integrated Pechora Expedition. - Issue. 1 (17). - 2016. - P. 171-172.

8. Popov K. Zyryane and Zyryan Territory// Izvestia IOLEEE. -T. XI-II. - Issue. 2. - M., 1874. - 89 p.

9. Vologdin P.V. Forest kingdom // Word. St. Petersburg, 1878. -73 p.

10. Zavyalov B.M., Vatlin A.V., Lomov V.E., Korableva N.N. Gladilov Valentin Vladimirovitch: pages of life in medical education (biography, works on the history of public health and medical education in the Komi Republic). - Kirov, 2015. - 368 p. 